\section{Alcohol-related liver cirrhosis in Poland: the reservoir effect}

Before 2002, deaths due to alcoholrelated liver cirrhosis were less common in Poland than in neighbouring countries, including Hungary, Lithuania, and Estonia. ${ }^{1,2}$ Since then, changes in alcohol consumption have been associated with markedly increased mortality from alcoholrelated liver cirrhosis. ${ }^{1,3,4}$

Between Jan 1, 2003, and Dec 31, 2017, alcohol consumption in Poland increased from 6.5 L per capita per year to more than $10 \mathrm{~L}$ per capita per year. ${ }^{3,4}$ We have previously described the marketing strategies used by the alcohol industry and the mistakes in health policy (including a decrease in excise duty on spirits by $30 \%$ in August, 2002) that facilitated these changes. ${ }^{3,4}$ The strategies and policies were associated with a dramatic increase in mortality from alcohol-related liver cirrhosis in both men and women of all ages and all educational groups, but especially 45-64-year-old women who had received $0-8$ years of education. Between Jan 1, 2002, and Dec 31, 2017, mortality from alcohol-related liver cirrhosis increased from 1.1 individuals per 100000 people per year to $7 \cdot 2$ individuals per 100000 people peryear in women aged 20-64years, and from 6.5 individuals per 100000 people per year to 20.0 individuals per 100000 people per year in men of the same age. The absolute number of deaths from alcohol-related liver cirrhosis per year in the 20-64-yearold group increased in the same period from 146 to 1032 women and from 804 to 2753 men (appendix).

Development of alcohol-related liver cirrhosis requires prolonged heavy drinking, which would suggest that there would be a lag between a policy change and deaths. Yet the Polish example adds to a growing literature base that changes in aggregate alcohol consumption can have an almost immediate, sharp effect on cirrhosis mortality at a population level. This phenomenon, known as the reservoir effect, was first described after the German occupation of Paris during World War 2. Between 1942 and 1947 an $80 \%$ decline in alcohol consumption was reported, accompanied by a rapid decrease in mortality from alcoholrelated liver cirrhosis by more than $50 \%$ by 1943 and more than $80 \%$ by 1947 . This phenomenon of rapid peaks and troughs in mortality from alcohol-related liver cirrhosis has been observed in eastern Europe. ${ }^{2}$ For example, the introduction of restrictions on alcohol availability in the Soviet Union under Mikhail Gorbachev's anti-alcohol campaign from 1984 to 1987 led to a decrease in alcohol consumption by about $25 \%$ and an immediate fall in mortality from alcohol-related liver cirrhosis of more than $40 \%$ in men and $35 \%$ in women aged 20-64 years. By contrast, the breakup of the Soviet Union between 1992 and 1995 was accompanied in many countries by rapid spikes in alcohol consumption immediately followed by increases in mortality from alcohol-related liver cirrhosis. In Russia, mortality from alcohol-related liver cirrhosis increased by $140 \%$ during the same time period. ${ }^{2}$

The developments in Poland since 2002 provide a new opportunity to observe an epidemiological phenomenon that remains only partly understood. However, it is becoming increasingly clear that in many European countries, including countries with otherwise strong public health measures such as Finland, alcohol is treated as a normal commodity. ${ }^{5}$ This Polish example shows how, in a 15-year period in the 21st century, weakening of previously effective strategies to limit alcohol availability, coupled with promotional activities by the alcohol industry, can create a health catastrophe.
We declare no competing interests.

*Witold A Zatoński, Mateusz Zatoński, Kinga Janik-Koncewicz, Martin McKee wazatonski@promocjazdrowia.pl

European Observatory of Health Inequalities, Calisia University, Kalisz, Poland (WAZ, MZ, KJ-K); Health Promotion Foundation, Nadarzyn, Poland (WAZ, KJ-K); Department for Health, University of Bath, United Kingdom (MZ); and Department of Health Services Research and Policy, London School of Hygiene and Tropical Medicine, United Kingdom (MM)

1 GBD 2017 Cirrhosis Collaborators. The global, regional, and national burden of cirrhosis by cause in 195 countries and territories, 1990-2017: a systematic analysis for the Global Burden of Disease Study 2017. Lancet Gastroenterol Hepatol 2020; 5: 245-66.

2 Zatoński WA, Sulkowska U, Mańczuk M, et al. Liver cirrhosis mortality in Europe, with special attention to Central and Eastern Europe. Eur Addict Res 2010; 16: 193-201.

3 Zatoński WA. The alcohol crisis in Polish public health. J Health Inequal 2019; 5: 122-23.

4 Zatoński WA, Młoźniak I, Zatoński M, Gruszczyński Ł. Small bottles - huge problem? A new phase of Poland's ongoing alcohol epidemic. J Health Inequal 2019; 5: 86-88.

5 Zatoński WA, Sulkowska U, Zatoński MZ, Herbeć AA, Muszyńska MM. Alcohol taxation and premature mortality in Europe. Lancet 2015; 385: 1181. 